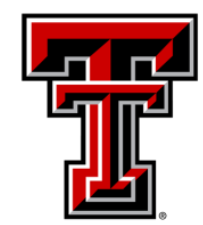

TEXAS TECH UNIVERSITY

Libraries"

\title{
A Selective Bibliography of Handbooks in Clinical Psychology
}

The Texas Tech community has made this publication openly available. Please share how this access benefits you. Your story matters to us.

\begin{tabular}{|l|l|}
\hline Citation & $\begin{array}{l}\text { Brian Quinn (1993) A Selective Bibliography of Handbooks in Clinical } \\
\text { Psychology, Behavioral \& Social Sciences Librarian, 12:2, 71-105, } \\
\text { https://doi.org/10.1300/J103v12n02_05 }\end{array}$ \\
\hline Citable Link & $\underline{\text { http://hdl.handle.net/2346/1514 }}$ \\
\hline Terms of Use & $\underline{\text { CC-BY }}$ \\
\hline
\end{tabular}




\title{
A Selective Bibliography of Handbooks in Clinical Psychology
}

\author{
Brian Quinn
}

\begin{abstract}
The explosive growth of clinical psychology literature has made it difficult for anyone to get a comprehensive overview of the field. Clinical psychology handbooks help alleviate this problem by providing a thorough survey of the discipline. Despite their utility for both students and librarians, no literature reviews of handbooks in clinical psychology currently exist. The present study seeks to fill this gap by selectively reviewing handbooks currently available, as well as a few "classics."
\end{abstract}

\section{PREFACE}

Clinical psychology has undergone extraordinary growth in the last thirty years. Raymond J. Corsini notes in The Encyclopedia of Psychology, Vol. 2 (New York: John Wiley \& Sons, 1984) p. 118, that, according to the 1981 APA Directory, Clinical Psychology was the largest of the 35 APA divisions, followed by the Division of Psychotherapy, each enrolling more than eight percent of the APA membership. According to Corsini, clinical psychologists are also identified with at least six other divisions: Counseling, Rehabilitation, Community, Hypnosis, Retardation, and Child and Youth Service. A new division of Health Psychology has been approved, along with a Division of Psychoanalysis. Over the years, seven

Brian Quinn is a recent graduate of the Graduate School of Library and Information Science at the University of Illinois.

Address correspondence to the author at 83 Violet Avenue, Floral Park, NY 11001.

Behavioral \& Social Sciences Librarian, Vol. 12(2) 1993

(C) 1993 by The Haworth Press, Inc. All rights reserved. 
members of Division 12 (Clinical) have served as APA president: Carl Rogers, E. Lowell Kelly, Paul Meehl, Abraham Maslow, George Albee, Theodore Blau, and Nicholas Cummings.

Along with this explosive growth in clinical psychology has come an equal mushrooming of clinical psychology research in the form of books and articles. Yet, as Raymond G. McGinnis suggests in Research Guide to Psychotherapy (Westport, Ct: Greenwood Press, 1982) p. xvi, this burgeoning literature has created problems for the researcher interested in finding information about clinical psychology or one of its many topics. The proliferation of material has made it extremely difficult for anyone to get a comprehensive overview of the field.

Handbooks in clinical psychology are designed to alleviate this problem. In a single volume they typically give an overview of the field by bringing together a collection of articles written by recognized experts who utilize the most current research available. A researcher can examine the entire volume for a comprehensive survey, or select a particular chapter for an in-depth examination of a particular subtopic. Not only are the individual chapters more thorough than most textbooks, they offer an additional advantage. A particularly valuable feature, according to Jeffrey G. Reed and Pam M. Baxter's Library Use: A Handbook for Psychology, Second Edition (Washington, D.C.: American Psychological Association, 1992) p. 13, is that they are accompanied by extensive reference lists.

Yet despite their obvious usefulness for both students and librarians seeking a starting point for a research topic, no literature reviews of handbooks in clinical psychology currently exist. The present study seeks to fill this gap in the literature by selectively reviewing handbooks currently available, as well as a few "classics."

This review is selective in that only general clinical psychology handbooks are reviewed. For example, handbooks on psychiatry and neuropsychiatry have not been included due to their biological emphasis. Similarly, handbooks devoted to particular therapies constitute a vast literature of their own and are therefore properly the subject of another essay. The only exception is behaviorism and cognitive behavioral therapy, which has become so pervasive that it is impossible to write an essay on handbooks and avoid it. The focus of this essay is on relatively recent works, published after 1980. Any relevant titles published prior to that date that still appear in Sheehy's Guide to Reference Books were also considered for inclusion.

The criteria used for evaluating the handbooks discussed in this review have been adapted from those mentioned by Patricia F. Stenstrom in her article "Almanacs, Yearbooks and Handbooks," in Richard E. Bopp and Linda C. Smith, editors, Reference and Information Services: An Introduction (Englewood, Co: Libraries Unlimited, Inc., 1991) p. 279. Some of the more important criteria include the work's authority, judged by the reputation of the author and the publisher. The scope of a work, including its stated purpose, comprehensiveness, and the degree to which the author has fulfilled his purpose, is another criterion. The book's arrangement was another consideration, including its organization, ease of use, and access, as judged by the table of contents and indexes. A fourth indicator was the author's treatment of the subject, such as the balance in covering certain topics, as well as the book's suitability for various types of audiences and libraries. A final consideration was the book's uniqueness, as judged by any special features in evidence, as well as the degree to which the book overlapped with other works in the field.

\section{THE HANDBOOKS}

C. Eugene Walker and Michael C. Roberts, editors. Handbook of Clinical Child Psychology, Second Edition. New York: John Wiley \& Sons, 1992. 1145 pages. ISBN 0-471-50361-4.

This second edition, part of the well known Wiley Series on Personality, is an update of the 1983 edition, which has become a standard reference in the field of clinical child psychology. One of the editors, C. Eugene Walker, is affiliated with the University of Oklahoma Medical School, and the other, Michael C. Roberts, is on the faculty of the University of Kansas (note: all author/editor affiliations are for the period during which they published the book). The many contributors to this massive volume have similarly solid academic credentials. Each article concludes with an extensive list of references for further reading.

The editors' stated purpose is to provide a comprehensive text 
and reference work covering the range of children's psychological problems that confront child psychologists. The emphasis is on practice, intervention, and management, but research has not been neglected. Most authors are both scholars and clinicians. Each article begins with a scholarly review of research in the area, followed by practical suggestions and advice. Areas covered include child development, diagnostic assessment of children, problems of early life confronting the neonate, infant, and preschool child, and problems of childhood such as anxiety, psychosomatic illness, toileting, sexual, eating, and learning problems.

A separate section on "Problems of Adolescence" covers problems with parents, mood disorders, depression, suicide, puberty and sex role problems, eating disorders, school problems, career choice, alcohol and drug abuse, and delinquency and criminal behavior. This is followed by a section on "Intervention Strategies" that includes behavior therapy, psychotherapy, family therapy, biofeedback, residential and inpatient treatment, hospitalization and medical care, and pharmacotherapy. A final chapter on "Special Topics" covers black children, sex education, prevention, child maltreatment, reactions of kids to divorce, grief and loss in childhood, ethical and legal issues and forensic evaluations. The scope is truly comprehensive, and many of the articles go into some depth. Articles are arranged chronologically from the child's earliest years to adolescence. There are detailed author and subject indexes for easy access. This is a scholarly work intended for graduate students and practitioners. It is appropriate for academic and medical libraries. For its sheer scope of coverage, this work is hard to equal.

C. Eugene Walker, editor. The Handbook of Clinical Psychology: Theory, Research, and Practice, 2 Vols. Homewood, IL: Dow Jones Irwin, 1983. 1439 pages. ISBN 0-87094-319-7.

This two volume work is edited by $\mathrm{C}$. Eugene Walker of the University of Oklahoma Medical School, along with five consulting editors with similar academic credentials. It is part of the Dorsey Professional Series published by Dow Jones Irwin, a well known name in publishing. A long list of contributors with respected academic backgrounds appears in the front of the book.
The stated purpose of the book is to “... strike a balance between scholarly review of current research literature and enlightened suggestions toward the best clinical practice." The book does seem to cover both research and practice thoroughly, with chapters devoted to the history, methodology, diagnosis and assessment largely constituting volume one, and recent developments in various treatment modalities comprising volume two. Treatment modalities covered include neurosis, schizophrenia, impulse control disorders, substance abuse, sexual dysfunction, crisis intervention, cognitive behavioral medicine, and behavioral medicine itself, including lifestyle and prevention. Also included are chapters on relaxation and stress management training, family and group therapy, hypnotherapy, social and community interventions, biofeedback, psychopharmacology, children's disorders, cultural issues in psychotherapy, and two concluding sections on the practice of psychology and forensic psychology. Given the breadth and depth of its coverage, this work does appear to be quite comprehensive.

The general organization of the book's 43 chapters is to begin with the theoretical and move to the practical or applied aspects of clinical psychology. It includes a detailed table of contents and index making the contents easily accessible. Each chapter includes an extensive list of references for further research. Overall, the book's treatment of various therapeutic modalities seems even handed, with a possible slight bias toward behaviorism. This is a scholarly work suitable for academic libraries and perhaps medical libraries as well. The concluding section on the practice of psychology and forensic psychology, with its helpful chapters on starting and managing a practice, administration, ethics, and legal issues, will be especially useful to those just entering the field. This is an outstanding reference work.

Theodore Millon, Catherine Green, Robert Meagher, editors. Handbook of Clinical Health Psychology. New York: Plenum Press, 1982. 608 pages. ISBN 0-306-40932-1.

The three editors of this work are on the faculty of the University of Miami, and the list of contributors in the front of the book similarly consists mostly of academics. Plenum Press is a well known scholarly publisher, indicating this work is a serious effort. 
The editors outline a strong agenda in the preface as to why they created this specialized work. Its purpose is to challenge the hegemony of the behavioral medicine approach to clinical health psychology. They see the book as an alternative to doctrinaire behaviorism and sterile medical models. The overall content of the work does appear to be more eclectic, with attention focused on personality, social and cultural factors, and historical and philosophical issues as well as behavior.

The work is divided into three parts, with Part One being devoted to the knowledge domain of clinical health psychology. This includes chapters on psychobiological factors in bodily disease, psychological processes induced by illness, injury and loss, the risk and course of coronary artery disease, stressful life events, stress coping and illness, coping with acute health crisis, adaptation to chronic illness and disability. Part Two focuses on "The Clinical Settings of Health Psychology," covering such topics as the psychologist as health care clinician, pediatric psychology, geriatrics, liaison psychiatry, the social systems consultancy, and behavioral cardiology. Part Three consists of psychological assessment, the impact of life changes, spinal cord injury, chronic physical illness, the management of chronic pain, cognitive behavior therapy, hypnosis and patient centered technologies. Although the book is somewhat dated, it nonetheless remains valuable for its broad based eclectic approach that brings a variety of theoretical perspectives to bear on clinical health psychology. The arrangement of the chapters is from general/theoretical to specific/applied situations. There is a detailed table of contents broken down into sub-sections for easy reference, as well as author and subject indexes in the book. Each chapter is followed by an extensive list of references, and tables and graphs are used in various chapters. The uniqueness of this work lies in its catholic non-doctrinaire approach to the field.

Philip C. Kendall and James N. Butcher, editors. Handbook of Research Methods in Clinical Psychology. New York: John Wiley \& Sons, 1982. 728 pages. ISBN 0-471-07980.

The editors of this book are faculty members of the University of Minnesota, and the other contributors of the articles also come from similarly well known schools. The book is part of the aforemen- tioned Wiley Series on Personality Processes edited by Irving B. Weiner of the University of Denver.

The editors' stated purpose is to create a theoretically eclectic handbook that approaches clinical psychology from a strictly methodological orientation. The Handbook is thus designed to be "a comprehensive collection of theoretical and methodological papers that span the major research domains in the field of clinical psychology." The book covers five broad areas, with several chapters devoted to each. Part One covers perspectives on clinical research, and includes experimental contributions, ethical perspectives, and serendipity in research. Part Two is devoted to research strategies such as taxometric methods, circumplex models of interpersonal behavior, experimental methods in psychopathology research, animal models, and cross cultural research methods. Part Three is about assessment techniques, among them direct observation, self report inventories, and psychophysiological methods. Part Four is devoted to intervention strategies, and includes articles on therapy outcome research methods, single case experimental designs, individualized measures of psychotherapy outcome, and research design and methods in community psychology. The final section, Part Five, covers research methods in developmental psychopathology, contemporary medical psychology, and clinical neuropsychology research. True to their purpose, the editors cover a lot of methodological ground in this single volume. The only drawback is that some of the material has become slightly dated in the decade since its appearance. The chapters are arranged from the most general perspectives to the more particular studies of general populations. In addition to the table of contents, there are author and subject indexes as well. Each article features an extensive list of references. This is clearly a work for academic and research libraries and will be of primary interest to graduate students and researchers in the field. This is a good overview of the field of research methodology, though I'm not completely sure that its methodological approach is as broad as the authors claim. I was unable to find any mention of introspection or phenomenological approaches, which are nonetheless valid as methods, even though they may not be currently popular. 
Michael Hersen, Alan E. Kazdin, and Alan S. Bellack, editors. The Clinical Psychology Handbook, Second Edition. New York: Pergamon Press, 1991. 846 pages. ISBN 0-08-036441-1.

This handbook is a part of the Pergamon General Psychology Series. Its editors come from solid clinical psychology backgrounds including the University of Pittsburgh School of Medicine (Herzen), Yale University (Kazdin) and the Medical College of Pennsylvania (Bellack). A well known list of contributors with detailed
biographies can be found in the book.

The stated purpose of the editors is simply to present the reader with a review of contemporary theory, research, and practice, while preserving historical contributions of predecessors. The book is divided into six parts. Part One concerns general issues, such as theoretical foundations, clinical training, professional practice, mental health policy, professional relations, ethical and legal issues, and a chapter on clinical psychology and the political scene. Part Two is devoted to personality theories and models, with chapters on personality theory, learning, social interaction, and humanist, phenomenological, and existential approaches. Part Three is about research issues and problems, including case studies, experimental research, personality research, psychopathology, and treatment, as well as a chapter on statistical issues. Part Four concerns assessment and diagnoses, from classification to diagnostic interviewing to objective personality assessment, to intellectual assessment, to neuropsychological, behavioral, psychophysiological and medical assessment. Part Five covers treatment, and ranges from psychodynamic psychotherapy to phenomenological existential therapy, to behavior therapy, psychoanalysis with children, cognitive behavior therapy, group therapy, family therapy, psychopharmacology, health psychology, and issues related to minorities. The final section, Part Six, includes articles on primary prevention of psychopathology, community mental health, and the brief psychotherapies. Overall, this single volume work covers a huge amount of material, and is more theoretically eclectic than other general works like Walker's The Handbook of Clinical Psychology. It has a simple, logical layout, a detailed table of contents, author and subject indexes, and extensive bibliographies following each article. Its chap- ters on clinical psychology and the political scene and computers as diagnostic devices are original and valuable. It offers a genuinely balanced theoretical perspective and covers timely topics such as minorities and brief psychotherapy. It is clearly intended for an academic audience, but might be of use in medical or clinical settings as well. An outstanding contribution to the field that is likely to remain so given its breadth of coverage as well as its historical depth of treatment.

S. J. E. Lindsay and G. E. Powell, editors. A Handbook of Clinical Adult Psychology. Aldershot, England: Gower Publishing Limited, 1987. 800 pages. ISBN 0-566-05102-8.

The editors of this work are from the University of London (Lindsay) and University of Surrey, two well known English institutions. Though the Gower name is not as familiar as Wiley or Pergamon, most of the contributors come from the University of London and similar recognized affiliations.

According to the foreward, the handbook is meant to serve four useful functions, including broad and authoritative accounts of major topics, as a reference tool for consultation, as a textbook for courses, and as a source for medical psychology. The handbook features a very practical, no nonsense approach which arranges subject matter by psychological problems, with the first half of each presentation being devoted to investigation and the second half to treatment. Among the problems covered are obsessions and compulsions, depression, fears and anxiety, sexual dysfunction, social behavior in adults, marital dysfunction, and schizophrenia. There is a notable absence of theory, philosophy, or history in the book, with the bulk of the text going to descriptions of techniques and procedures. Clinical skills such as chairside manner are not in evidence, nor are important professional matters such as ethical concerns. The authors state in their introduction that they feel such topics are beyond the scope of their book. Yet this is hard to justify when other handbooks are including such material. Nonetheless, the articles do appear thorough within this book's relatively limited scope. Each is accompanied by a detailed bibliography. There are both author and subject indexes. The treatment of the subject itself doesn't appear to 
be especially broad or eclectic. Indeed, the whole approach is almost atheoretical and concerns itself almost solely with praxis. In general, this work lacks the breadth and depth of some of its Ameri can counterparts, most notably Hersen et al.'s The Clinical Psychol. ogy Handbook, which manages to cover a good deal more ground in roughly the same number of pages. Still, the book is interesting for its British viewpoint and is worth reading for the cultural perspective it affords.

Benjamin B. Wolman, editor. Handbook of Clinical Psychology. New York: McGraw Hill, 1965. 1596 pages. No ISBN.

The editor of this volume, Benjamin B. Wolman is a faculty member of Adelphi University's prestigious Institute of Advanced Psychological Studies. The contributors listed have similarly sound credentials. The publisher is the reputable McGraw Hill firm, which suggests this is a quality reference work.

The editor states in the preface that his purpose is to create the first handbook of clinical psychology, because at that time there were none. The handbook is divided into six parts, of which the first is devoted to research methods and covers case studies, experimental methods, and statistics. The second part covers theoretical formulations including genetic and biochemical factors, society and individual behavior, cultural determinants, behavior therapy, personality theory, and psychoanalytic theory. Part Three covers diagnostic methods such as differential diagnosis, the interview, personality inventories, intelligence tests, projective techniques, and other methods. Part Four addresses clinical patterns like organic mental disorders, seizures, speech disorders, disability, aging, mental deficiencies, psychosomatics, neuroses, schizophrenia, and depression, addiction, delinquency, and other topics. Part Five is devoted to treatment methods, including psychoanalysis, behavior therapy, group therapy, hypnotherapy, psychopharmacology, hospital care, and prevention. The final chapter is devoted to clinical psychology as a profession, and includes chapters on graduate education in psychology, postdoctoral training, the profession, clinical psychologists at work, relations with other professions, international trends, and ethics. This is a truly comprehensive work, with many of the articles going into considerable depth and accompanied by long bibliographies. The material is by now dated, but nonetheless represents a balanced, eclectic approach to its subject matter that still makes it seem more contemporary than it is. It is still useful as a reference work and for historical research, with interesting chapters on topics such as international trends in clinical psychology. While it is hard to call anything "classic" in a scientific field such as psychology, this work manages to come close. It includes excellent author and subject indexes.

Jerry J. Sweet, Ronald H. Rozensky and Steven M. Tovian, editors. Handbook of Clinical Psychology in Medical Settings. New York: Plenum Press, 1991. 642 pages. ISBN 0-306-43550-0.

These editors are unquestionably well qualified to undertake this work, given their affiliation with Evanston Hospital, Northwestem University, and Northwestem University Medical Center. Many of the other contributors to this volume also have similar appointments. The publisher, Plenum Press, is a recognized name in the field of academic publishing.

The editors' purpose is to provide a range of possible topics that exemplify the overall scope of clinical psychology in medical settings. They readily admit that they restricted the size and range of topics to what could reasonably be covered in a single volume. They have divided the work into seven parts. Part One is an introduction to clinical psychology in health care settings. Part Two focuses on professional issues such as clinical training, hospital politics, and professionalism in medical settings. Part Three is concerned with practical issues such as quality assurance, and financial management. Part Four is devoted to clinical issues like consultation, and women's health and the elderly, while Part Five concerns itself with research issues, particularly implementing the scientist practitioner-model. The sixth chapter is devoted to program development and focuses on testing programs, eating disorder programs, oncology programs, diabetes, asthma, gastrointestinal, hemodialysis, dental, and AIDS programs. The material is organized from more general topics to more specific ones. There is a general table of contents and a combined author/subject index, so access is not 

particularly easy. However, detailed biographical sketches are pro.
vided in the back of the book.

This handbook takes a very practical approach and generally avoids much theoretical material. Its discussions of politics, care of women and elderly, AIDS treatment, and the use of computers in psychological practice make it worth reading. Each article appears to be in-depth and includes an extensive bibliography. This book would be of interest to academic libraries and medical libraries, and is aimed at graduate students and practitioners in the field. It is much more up to date than Millon, Green, and Meagher's Handbook of Clinical Health Psychology, but it lacks the latter's broadly theoretical and eclectic framework for analyzing clinical problems. Ideally, one should look at both to get a true sense of how rapidly this new specialty has evolved.

C. R. Snyder and Donelson R. Forsyth, editors. Handbook of Social and Clinical Psychology: The Health Perspective. New York: Pergamon Press, 1991. 878 pages. ISBN 0-08-036128-5.

This work is part of the Pergamon General Psychology Series issued by this well known firm. C. R. Snyder is affiliated with the University of Kansas and Donelson R. Forsyth with Virginia Commonwealth University. There is a section in the back of the book offering detailed biographical sketches of the contributors. These indicate that the contributors also have solid credentials and affiliations.

The editors' stated intention in this volume is to bring together in a single work articles that cross the traditional boundaries between social and clinical psychology, thus creating an interface between them. The authors feel that the interdisciplinary nature of the health field makes it a natural setting for such a merging of perspectives. The book is divided into four parts comprising forty chapters. The first part is on the uniting of clinical and social psychology, and is followed by Part Two, which covers person-based processes. Person-based processes include chapters on the terror management theory of self esteem, the role of humor and the self, self efficacy, reality negotiation and excuse making, coping with accountability, gender roles and health, coronary proneness, affective dispositions in physical and psychological health, explanatory style, helplessness and depression, and hope and health. Part Three is concerned with environment based processes, and includes chapters on close relationships, an interactional perspective on depression, interpersonal analysis of the help-seeking process, coping implications of loneliness, clinical judgement and decision making, interpersonal methods of assessment, and much more. Part Four focuses on present paradigms and future directions, including methodological challenges, metatheoretical and epistemological issues, and education and training. The book includes a detailed table of contents along with author and subject indexes. It is practical yet broadly theoretical, and includes a variety of theoretical approaches including cognitive-behavioral interventions and hypnosis. This book is intended for academic and medical libraries, and will be of interest to both clinical and social psychology students and medical sociologists. Its uniqueness lies in its ground breaking interdisciplinary synthesis that makes it one of the most unusual and original handbooks on clinical psychology ever written. It offers an extremely broad array of subject coverage, along with articles on specific topics that go into considerable depth and include detailed and lengthy lists of references. The book is lucidly written, exciting to read, and fills an important gap in the field. One can only hope other psychologists will take note and follow its example with similar interdisciplinary breakthroughs that prove to be as ambitious and rewarding as this one.

Michel Hersen and Alan S. Bellack, editors Handbook of Clinical Behavior Therapy with Adults. New York: Plenum Press, 1985. 732 pages. ISBN 0-306-41875-4.

Both of the editors of this handbook are affiliated with prominent institutions-Michel Hersen with Western Psychiatric Institute and the University of Pittsburgh School of Medicine, Allan Bellack with Medical College of Pennsylvania at EPPI. The list of contributors provided in the front of the book indicates a similarly qualified group of authors participated in the writing of this work. Plenum Press's authority has been mentioned previously.

The aim which the editors stated in the preface was simply to look at the contemporary work in behavior therapy that is being 
carried out with adults. The authors point out that although they have chosen to highlight the clinical aspects of these endeavors, they have not slighted the research end of the field. The book is divided into six parts. Part One is simply an introduction by the editors. This is followed by a section on anxiety disorders consisting of chapters on simple phobia, agoraphobia, stress and generalized anxiety, social anxiety, and obsessive-compulsive disorders. Part Three is devoted to depression, with chapters on cognitive approaches and social skills training approaches. Part Four focuses on behavioral medicine, with chapters on obesity, anorexia nervosa, alcohol and drug abuse, insomnia, pain, cardiovascular disorders, and headaches. Part Five covers inpatient and outpatient treatment of schizophrenia, and Part Six encompasses special problems such as unassertiveness, sex roles, work and study problems, aging, anger and violent behavior, sexual deviation, psychosexual dysfunction, and marital dysfunction. The book thus covers a wide range of topics within a limited scope. Subject access is merely average, with a general index and table of contents. The theoretical approach of the book is limited to a behaviorist perspective, which makes it of primary interest to behaviorally oriented therapists. More general readers might be disappointed with so narrow a focus. Overall, this work represents a very specialized treatment of a rather specialized topic, and will be useful for academic and research libraries serving graduate programs in psychology. Medical libraries may also find the lengthy chapter on behavioral medicine useful. Anyone needing a handbook in the traditional sense of offering a comprehensive overview of a discipline would be advised to look elsewhere.

Alan M. Gross and Ronald S. Drabman, editors. Handbook of Clinical Behavioral Pediatrics. New York: Plenum Press, 1990. 428 pages. ISBN 0-306-43180-7.

Both editors of this book are affiliated with the University of Mississippi, Alan Gross with the university itself and Ronald Drabman with the University of Mississippi Medical Center. The list of contributors in the front of the book are also affiliated with recognized institutions. This work is part of Plenum's Applied Clinical Psychology Series.

The editors' purpose is to focus on the practical, applied issues in behavioral pediatrics and to make readers familiar with several newly emerging areas of behavioral pediatrics. The book thus has two different sections devoted to disorders. One focuses on more traditional problems, the other on more recent problems. Part One of the book covers basic principles, including inpatient and outpatient treatment, developmental issues, and assessment strategies. Part Two is concerned with clinical disorders, with chapters on cognitive-behavioral assessment and treatment of pediatric pain, headache, eating disorders, childhood cancer, and diabetes, bladder control, asthma, and childhood sleep disorders. Part Three focuses on newer areas of clinical intervention in behavioral pediatrics, and includes pediatric burns, tics and Tourette's Syndrome, behavior therapy in cystic fibrosis, allergies, pediatric dentistry, and other problems. The final part of the book covers general issues such as preparing children for hospitalization and threatening medical procedures, pediatric patient compliance and accident prevention.

The arrangement of chapters is roughly chronological, with more established problems followed by more recent ones. There is a general table of contents and index. The book is intended for graduate students and clinical practitioners and is suitable for academic and medical collections.

This work is valuable because it covers a limited area of the clinical psychology field in considerable depth, with a wide range of well researched articles. Its principle drawback is that it limits its coverage of more theoretical issues, and adheres principally to behavioristic principles in its treatment of issues. It is mainly a treatise on applied behaviorism within the context of a newly emerging and rapidly developing field. For a somewhat more eclectic approach, one needs to refer to Walker and Roberts' Handbook Of Clinical Psychology, though it doesn't cover medical aspects in quite as much depth as this work.

Sol L. Garfield and Allen E. Bergen, editors. Handbook of Psychotherapy and Behavior Change. New York: John Wiley \& Sons, 1986. 886 pages. ISBN 0-471-79995-5.

Sol Garfield is a psychologist at Washington University and Allen E. Bergen is affiliated with Brigham Young University. A list of contributors with first rate credentials were also involved in this 
work. The publisher is John Wiley \& Sons, one of the more distin. guished names in publishing.

The editor's purpose is to present a ". . . critical appraisal of existing empirical research findings with an even handed or eclectic attitude toward divergent orientations in the area of psychotherapy and behavior change along with their implications for research and practice." Their book is divided into six parts. Part One deals with historical, methodological, and conceptual foundations, including chapters on social psychological approaches as well as developmental perspectives. Part Two is concerned with evaluation of process and outcome in psychotherapy, and includes chapters on effectiveness, client variables, therapist variables, and process and outcome. Part Three is devoted to behavioral and cognitive therapies, including a chapter on behavioral medicine and health psychology. Part Four covers child and family therapies, including behavior therapy with children and research on marital and family therapies. Part Five concerns itself with special topics such as brief psychotherapy, group therapy, educational and vocational counseling, psychotherapy with the disadvantaged, and drugs and psychotherapy. The last section is devoted to research on the teaching and learning of therapeutic skills. There are both name and subject indexes for easy access, as well as a general table of contents. This is a general handbook covering a wide array of material. The individual articles are quite detailed and well researched.

My one concern is that the author's purported "even handed" approach seems to exhibit a rather strong behavioral bias that makes it appear less eclectic than it's stated intent. Perhaps this simply reflects the dominance of the behaviorist paradigm in the field, but the authors should make this clear if this is the case. To say a work is eclectic when it shows a strong theoretical bias is misrepresenting one's work. This is especially important in light of the fact that this handbook is widely used as a textbook in clinical psychology graduate programs. Many of the readers of this book, being novices in the field, may not realize that what they are reading represents a limited point of view.
Leopold Bellak and Helen Siegel. Handbook of Intensive Brief and Emergency Psychotherapy. New York: C.P.S., Inc., 1983. 169 pages. ISBN 0-918863-00-7.

Leopold Bellak, M.D., is Clinical Professor Of Psychiatry at Albert Einstein College of Medicine and Clinical Professor of Psychology at New York University. Helen Siegel was, at the time of writing, a doctoral candidate in clinical psychology at Yeshiva University. The publisher is C.P.S., Inc. of Larchmont, New York, a rather obscure name in the field, but Bellak himself is widely known.

The authors open this brief work by explaining that the original idea of a handbook was a book small enough to be held in one hand-to be handy. "That is the purpose, literally and figuratively, of this book: we want it to be handy in format and content." The authors hope to make the basic principles and techniques of psychotherapy accessible by discussing ten of the most frequent psychogenic conditions experienced by clinicians. There is no attempt to be comprehensive. From these ten, the authors believe, it will not be difficult to extrapolate techniques to other conditions not mentioned.

The work is divided into two parts. Part One consists of general propositions, including the ten basic tenets of intensive brief and emergency psychotherapy, the initial session, the second through sixth sessions, the therapeutic process, and methods of intervention. Part Two consists of discussions of specific conditions such as depression, acting out, suicide, psychotic states, physical illness or surgery, catastrophic life events, phobias and anxiety hysterias, panic, and feelings of unreality. The book concludes with a sample intake interview. There is a bibliography, as well as subject and author indexes. The chapters themselves are brief, concise, and written in such straightforward, clipped sentences that at times they almost read like recipes in a cookbook. This is an extremely compact discussion of clinical problems that manages to squeeze a tremendous amount of material into a brief manual.

The overall emphasis is on practical problem solving, yet a number of theoretical issues are covered. There is a strong psychoanalytical flavor to the work, perhaps reflecting Bellak's psychoanalytic 
training in Vienna. This work is intended for clinical psychologists and psychiatry residents, but would also be of use to clinical social workers as well. It is well suited to academic and medical libraries, as well as libraries of public welfare agencies. Its uniqueness lies in its remarkable brevity and no nonsense approach that talks almos solely in terms of problems, symptoms, interventions, and solutions. It reads like a first aid manual for the psyche, the kind of book one could pick up and thumb through quickly in a crisis and pinpoint the most appropriate treatment needed to alleviate a patient's symptoms. It looks to be, as the authors intended, extremely handy.

Alan S. Bellack and Michel Hersen, editors. Handbook of Comparative Treatments for Adult Disorders. New York: John Wiley \& Sons, 1990. 556 pages. ISBN 0-471-62588-4.

As mentioned previously, Alan S. Bellack is a clinical psychologist in the Department of Psychiatry at the Medical College of Pennsylvania in Philadelphia. Michel Hersen is affiliated with the Department of Psychiatry at Western Psychiatric Institute and Clinic in Pittsburgh. The book is part of the previously mentioned Wiley Series on Personality.

The editors describe their purpose as the presentation of an overview of the best current thinking and techniques, from two or more major different viewpoints, on each of the major adult disorders, so as to permit easy comparison for student or professional. The book consists of nine parts. Part One covers current directions, with chapters on psychotherapy, behavior therapy, and pharmacotherapy. Part Two is on depression, and features a special chapter on social skills training. Part Three deals with panic and agoraphobia, Part Four is about social phobia, with a chapter on cognitive behavior therapy, Part Five is devoted to obsessive compulsive disorders, Part Six to post traumatic stress disorder, Part Seven to anorexia and bulimia, Part Eight to borderline personality disorder, and Part Nine to alcoholism and substance abuse. Author and title indexes follow.

Most parts are approached from three viewpoints: psychotherapy, behavior therapy, and pharmacotherapy, and conclude with an editorial commentary. What the editors never comment on, though, is why psychotherapy and behavior therapy are in separate chapters to begin with. For a genuinely balanced approach, it seems there should be only two chapters, one on psychotherapy and one on pharmacotherapy. Why is behavior therapy not simply part of the psychotherapy chapter?

Each chapter is well detailed and well researched, with an extensive bibliography, but this does not make up for the lack of balance in coverage. This is a book intended for graduate students in clinical psychology a well as practicing professionals, and would be appropriate for university libraries and some medical school and hospital libraries. It is baffling why the authors have failed to achieve in this work the admirable balance they maintained throughout their outstanding work, The Clinical Psychology Handbook. Oddly enough, for a work that calls itself a Handbook of Comparative Treatments for Adult Disorders, it is actually less comparative in its approach than the more eclectic Clinical Psychology Handbook.

Robert G. Meyer. The Clinician's Handbook: The Psychopathology of Adulthood and Adolescence, Second Edition. Boston: Allyn \& Bacon, 1989. 419 pages. ISBN 0-205-11922-0.

Robert G. Meyer is a psychologist on the faculty of the Department of Psychology at the University of Louisville. The publisher, Allyn \& Bacon, is a well known and highly reputable publishing company.

The purpose of this work is to integrate common symptoms and general behavior patterns with the major psychodiagnostic categories and data from psychological tests such as the Minnesota Multiphasic Personality Inventory (MMPI), the Wechsler Adult Intelligence Scale Revised (WAIS-R), Rorschach, and the Thematic Apperception Test (TAT). The book is organized into sixteen chapters, covering substance use disorders, schizophrenic and paranoid disorders, mood disorders, anxiety disorders, somatoform disorders, dissociative and sleep disorders, sexual disorders, personality disorders, the criminal personality, disorders of impulse control, malingering and factitious disorders, aggression, child abuse, suicide, hyperactivity, retardation, and a final chapter on professional case preparation and presentation that covers malpractice and serv- 
ing as an expert witness. There are two appendices on testing and chemotherapy, as well as a bibliography and subject and name indexes for easy access. There is also a detailed table of contents that makes it easy to locate subtopics.

The book is well organized, with subheadings noting topics within chapters. It is aimed at practitioners in psychology, social work, nursing and education, but is also suitable for use in graduate courses in psychology. It is appropriate for academic, medical and public welfare agency libraries. The book is unusual in that it relies heavily on testing categorization and scores to diagnose disorders as well as to measure progress in treatment of these problems. Its final chapters on criminal insanity and professional case preparation are also unusual for this genre of publication, and should prove useful to anyone involved with forensics or who is otherwise interested in these neglected areas of the literature. The chapters discuss in detail the prevention of malpractice suits from clients, and the clinicians's role serving as an expert witness for a client. The book's unusual contributions in these areas and its atypical approach to clinical practice through testing make it worthy of consideration in collec-
tion development.

Eric Margenau, editor. The Encyclopedic Handbook of Private Practice. New York: Gardner Press, Inc. 1990. 1048 pages. ISBN
0-89876-151-4.

Eric Margenau, who has a Ph.D. in clinical psychology from New York University, is executive director of the Center for Sports Psychology and also maintains a private practice in New York City. The majority of contributors to this volume are listed as being similarly involved in private practice in psychology. The publisher is Gardner Press, whose reputation is somewhat obscure.

The handbook's stated purpose is to cover the broad range of factors outside of actual clinical training that affect the success of the private practice venture. It is divided into five parts. Part One covers practice management issues such as organizing a practice, designing and managing an office, record keeping, referrals, and marketing and advertising. Part Two deals with financial and economic management practices, including insurance, fees, collec- tions, specialization, incorporation, and taxes. Part Three is concerned with emotional issues in private practice such as public perception, personal life, stress, loneliness and isolation, retirement, countertransference issues, and gender and ethnicity considerations. Part Four consists of legal and ethical issues including professional ethics, liability, litigation, confidentiality, termination, automation, and forensics. Part Five treats philosophical, theoretical and technical issues, and includes typical mistakes practitioners make, boredom and burnout, the management of therapeutic crises, regional differences in treatment, length of treatment, business acumen, consulting, collaboration, and group therapy. The chapters are generally detailed and well researched, with accompanying bibliographies. An author and subject index are included.

Although the book is intended for private practitioners, it covers issues that would be of interest to any practicing clinician, as well as graduate students in clinical psychology. It is appropriate for academic libraries, and social welfare agency libraries as well. This book's emphasis on issues of practice rather than on diagnosis makes it somewhat unique and helps fill a gap in the literature. It is refreshing to come across a book that focuses so completely on practitioners rather than patients, and it thus should prove extremely valuable to practitioners who are human and have problems that need to be addressed as well as do patients. One unfortunate drawback of this otherwise interesting book is that it is marred by poor editing and contains numerous misspellings and malapropisms. But if one can manage to overlook this, the book's content is fascinating and rewarding and would be a valuable part of any library's collection.

Benjamin B. Wolman, editor. The Therapist's Handbook: Treatment Methods of Mental Disorders, Second Edition. New York: Reinhold Company, 1983. 565 pages. ISBN 0-442-25616-7.

Benjamin B. Wolman, mentioned previously, is Professor Emeritus in the doctoral program at Long Island University. The contributors to this volume are all clinical psychologists with academic affiliations as well. The publisher is an established name in the field.

Although the editor does not explicitly state a purpose, the book represents an update of the first edition published in 1986, which was 
itself intended to give an overview of the state of the art in psychotherapy. Fourteen of the twenty-three chapters in the handbook are new The book is divided into two parts, "General Techniques" and "Spe. cialized Techniques." "General Techniques" includes chapters on patient-doctor relationships, psychopharmacology and ECT, psychoanalysis, behavior modification, hypnotherapy, interactional analysis, brief therapy, group therapy, hospital care, and preventive methods. Part Two, "Specialized Techniques," includes phenomenological ap. proaches to the treatment of organic psychiatric symptoms, geriatrics, schizophrenia, depression, neuroses, and borderline cases, antisocial behavior, drug addiction, alcoholism, psychosomatic disorders, and research in psychotherapy. Most of the chapters go into some detail and are followed by lengthy bibliographies. There are author and subject indexes, and the overall approach is applied rather than theoretical. A wide range of disorders is covered and the theoretical orientation is genuinely eclectic rather than doctrinaire. The chapters on interactional psychotherapy, preventive methods, and phenomenological approaches are all somewhat atypical and unique, as one rarely sees them mentioned in other handbooks. This book is intended for clinicians and students, and would be suitable for academic libraries, social agency libraries, and perhaps some medical libraries as well.

The book's principle limitations are its lack of theory and its age. It could use a broader historical and theoretical framework, in order to place its pragmatic chapters in context. The other concern is that some of its material, especially the chapters from the first edition, are beginning to sound a little dated because the field of clinical psychology is changing so rapidly. This is a major drawback in a work that was intended to be a state of the art summary of current therapeutic techniques. After a decade, The Therapist's Handbook is ripe for an updated, third edition.

Windy Dryden, editor. Individual Therapy: A Handbook. Milton Keynes, UK: Open University Press, 1990. 359 pages. ISBN
0-335-09446-5.

Windy Dryden teaches psychology at the University of London and is a Fellow of the British Psychological Society. The other contributors to this compact volume are clinicians, many of whom have academic affiliations. The publisher is Open University Press, which publishes several series in the field of clinical psychology.

This book is an update of an earlier 1984 edition entitled Individual Therapy in Britain. Its purpose is to survey well established approaches to individual psychotherapy in Great Britain. The book consists of fifteen chapters. Chapter One covers British psychotherapy in context, Chapter Two is concerned with Freudian psychodynamic therapy, Chapter Three with Kleinian therapy, Chapter Four with Jungian therapy, followed by chapters on Adlerian therapy, person-centered therapy, personal construct therapy, existential therapy, gestalt therapy, transactional analysis, cognitive therapy, behavior therapy, comparative approaches to individual therapy, research in individual therapy, and a final chapter on training and supervision of individual therapists. Each of the chapters is brief but thorough, and includes bibliographies. Each chapter is also structured so as to include the particular approach's views on how psychological change occurs, the selection criteria used by practitioners of the approach to determine whether or not clients will benefit from the approach, and the limitations of the approach. This consistent format makes it easier to compare chapters. There are two appendices, one outlining the chapter structure the contributors were asked to follow, the other listing information in clinical services and training opportunities offered by each approach. The book concludes with a combined author and subject index.

The book's non-technical approach would seem to indicate it is intended for a wider audience than the usual group of practitioners and students. It thus would be appropriate for academic as well as some larger public libraries in urban areas. The book is valuable not only for its broad eclecticism and accessibility, but its uniform chapter structure lends itself to a truly comparative approach. By consistently structuring the chapters, the differences and similarities of the therapeutic approaches are drawn into much sharper relief than most other handbooks. It would seem to be particularly useful to anyone attempting to choose an appropriate therapy from among the wide array currently available. 
David P. Ogdon. Handbook of Psychological Signs, Symptoms, and Syndromes. Los Angeles: Western Psychological Services, 1987. 102 pages. ISBN 0-87424-173-1.

David P. Ogdon is a psychologist on the faculty at Old Dominion University and Eastern Virginia Medical School. Western Psychological Services is a publisher that issues many titles in the clinical psychology area.

Although the author does not explicitly state the purpose of the book, it is an attempt to perform psychological assessment and diagnosis by matching a patient's signs, symptoms, and syndromes with indicators used in major psychological tests such as Wechsler, Rorschach, projective drawings, and Bender-Gestalt. The book is divided into seven chapters. After an introduction in Chapter One, the second chapter treats normality and minor personality anomalies, including psychological defenses and mechanisms, repression, regression, compensation, overcompensation, and reaction formation, fantasy, rationalization, intellectualization, isolation, projection, and defensiveness. Minor personality anomalies such as withdrawal, inhibition, and constriction, immaturity, dependency, insecurity, inadequacy, and inferiority are also covered. Chapter Three discusses neuroses and neurotic epiphenomena, anxiety, tension, modes of neurotic adjustment, and fears and phobias. Chapter Four is concerned with psychoses, reality ties, schizophrenia, paranoid suspiciousness, and manic depressive disorders. The fifth chapter deals with acting out, character, sexual aberrations, psychopathy, sociopathy, delinquency, and psychosexual disturbances. Chapter Six is devoted to organicity, and Chapter Seven to prognosis. Each chapter contains a detailed list of indices and signs, each with a reference to a corresponding study that discusses it in detail. These studies are referenced in a lengthy bibliography at the end of the book.

This work is appropriate for practicing clinicians and advanced graduate students and interns, as it assumes knowledge of personality theory and abnormal psychology, and extensive familiarity with projective psychology and psychological tests. It is suitable for academic and medical school libraries. This book bears some similarity to Robert G. Meyer's The Clinician's Handbook, in that it is concerned with testing, but lacks the much broader theoretical thrust of the latter. Ogdon's book is very narrowly focused and almost totally oriented toward the applied. Within its limited scope, it does seem thoroughly researched. It will be of most interest to clinicians who believe strongly in psychological tests and use them extensively in their practice. To those practitioners who view testing as just one element in a larger repertoire of diagnostic methods, however, this work may prove to be of limited interest.

Paul Pedersen, editor. Handbook of Cross Cultural Counseling and Therapy. Westport, CT: Greenwood Press, 1985. 353 pages. ISBN 0-313-23914-2.

Paul Pedersen is Chairman of the counseling and guidance program and Professor of Education at Syracuse University. Most of the contributors to this volume are psychologists or education faculty with academic affiliations. Greenwood Press is a well established publisher in the social sciences.

This book reviews the history, present status, fundamental assumptions, fundamental theories, and future directions of forty specializations within the broad field of cross cultural counseling. The work consists of five sections. Part One is concerned with counseling and therapy perspectives and explores cross cultural career counseling, cultural variations in clients, the social psychology of cross cultural counseling, and psychological disorders across cultures. Part Two covers counseling methods, including ethnographic methods, developing ethnic sensitivity, and nonverbal behavior. Part Three looks at client populations, including Native Americans, Asian Americans, Hispanics, and Blacks. Part Four is devoted to issues and research, touching on cross cultural assessment, existentialism as a counseling modality, sex role issues, east/west counseling, counseling and cultural identity, and social distance as an indicator of attitudes. Part Five covers mental health training across cultures, the status of racial and ethnic minority counseling, training issues in conducting therapy with ethnic clients, using natural support systems in cross cultural counseling, and intercultural criteria for mental health training.

The chapters are brief but insightful and cover a wide variety of 
material. Each includes helpful bibliographic references for further reading. There is a combined author and subject index as well as detailed biographies of the contributors. The intended audience for this book consists of both students and practitioners, and indeed any human services professionals who want to increase their cultural understanding and sensitivity. It is appropriate for academic libraries and human service agencies.

This book fills a special gap in the literature, the need for more cross cultural research and understanding of mental health and illness. This area has been neglected until quite recently, and deserves even more attention from researchers. Meanwhile, this book takes a great step forward in reducing the confusion of those in the mental health field who must navigate the intricate complexity of cultural beliefs, perceptions and practices.

Lynne Bravo Rosewater and Lenore E. A. Walker, editors. Handbook of Feminist Therapy: Women's Issues in Psychotherapy. New York: Springer Publishing Company, 1985. 352 pages. ISBN 0-826149700-7.

Lynne Bravo Rosewater is a psychologist in private practice in Cleveland, Ohio, and Lenore E. A. Walker has a private practice in Denver, Colorado. The contributors to this volume are primarily private practitioners with academic affiliations. The publisher, Springer, is well known in the field of psychology.

This volume grows out of the First Annual Advanced Feminist Therapy Institute, a gathering of 60 feminist therapists held in Vail, Colorado in April of 1982. Its purpose is to document the advanced clinical application of psychotherapeutic techniques with women. "Feminist therapy" thus refers not to a particular type of therapy but rather a therapy directed at a certain population and its problems. The book is divided into seven parts. Part One is concerned with a feminist philosophy of treatment and discusses barriers to its development, guidelines for feminist therapy, and the future of feminism. Part Two covers feminist psychotherapeutic techniques and practices, including assertiveness training, anger, body therapy, lesbian relationships, and sex therapy. Part Three focuses on women's issues across the life span, such as feminist spirituality, infertility, stepmothering, relationships, and aging. Part Four is concerned with violence against women, including therapy with victims and survivors, schizophrenia, battered women, and the role of pornography. Chapter Five treats power and advocacy issues and includes power in therapy, ambivalence about fees, feminist interpretation of testing, and feminist forensic psychology. Chapter Six briefly explores feminist ethics and includes dual relationships with clients, and ethics and business practice in feminist therapy. The final chapter is devoted to training feminist therapists, with chapters on teaching, course evaluation, and therapy supervision.

Chapters are concise but well researched, with references for further study. A subject index is included, but the volume could use an author index as well. There is a special section that outlines the principles concerning the counseling and therapy of women, and an epilogue consisting of the lyrics to two feminist songs written by one of the contributors.

In general, this book is a serious attempt to fill a gap in the research literature on the psychology of women. It is a highly polemical tract as well, and perhaps could have been helped by an attempt at a more neutral empirical stance, but its merits far outweigh its minor flaws. Though it is directed at clinicians, it should be of interest to anyone interested in gender issues, and would be suitable for academic as well as larger urban public libraries.

Murray Scher, Mark Stevens, Glen Good, and Greg A. Eichenfeld. Handbook of Counseling and Psychotherapy with Men. Newbury Park, CA: Sage Publications, Inc., 1987. 400 pages. ISBN 0-8039-2991-9.

Murray Scher is a counseling psychologist in private practice, Glen Good is a psychologist affiliated with the University of Southem California School of Medicine, Mark Stevens is a staff psychologist at USC's Student Counseling Center, and Greg Eichenfeld is a psychologist at the University of Oklahoma. Sage Publications is a well known publisher in the area of the social sciences.

The authors' stated purpose is to provide information that will enable practitioners and interns to understand the nuances of aiding male clients as well as having a sufficient repertoire of skills and 
techniques for implementing that understanding. The book is divided into five parts. Part One addresses techniques and perspectives, including men counseling men, women therapists and male clients, counseling men in groups, career counseling with men, therapy, and training for counseling merk with men, body focused therapy, and training for counseling men. Part Two covers develop. mental issues such as identity integration among adolescent males, men. Part Four issues among college men, and counseling aging men. Part Four is concerned with ethnicity and working with black, tions, such as gays, bisexuals. AIDS is devoted to special populadual career marriages, men in marital therapy, single fathers, men in in prison, male substance abusers, veterapy, men who batter, men men, and therapy with men in health vare

The chapters are briefer in health care settings. are accompanied by lists of references. There is a detailed tesearched and contents broken down into cross headings, and a separate section table of ample biographical detail about the has neither an author nor about the contributors. The book, however, intended for as wide an audience as possible, not only clinich. It is students, but anyone interested in gender issues. It would be suitable
for academic libraries, as well as some larger public libraries.

This work covers a broad as some larger public libraries. ethnicity, and economic background. Oddly en cerned with cerned with practice and applied skills that it is almost devoid of theory. It seems to be less polemical than the Handbook of Feminist Therapy. It represents an important pioneering effort, as does the Handbook of Feminist Therapy, to call attention to the importance of gender, gender roles, and expectations in influencing psychologi-
cal functioning.

Michael E. Thase, Barry A. Edelstein, and Michel Hersen, editors. Handbook of Outpatient Treatment of Adults: Nonpsychotic Mental Disorders. New York: Plenum Press, 1990. 684 pages.
ISBN 0-306-43267-6.

Michael Thase is affiliated with the Department of Psychiatry at a psychologist at West Virginia University, and Michel Hersen is with Western Psychiatric Institute in Pittsburgh. Most of the contributors have similar academic affiliations.

The stated purpose of the editors was to create a handbook focusing on the outpatient treatment of mental disorders that is both timely and useful. The book is divided into four sections. Section One covers general issues such as interviewing and diagnosis, differentiating physical from psychiatric disorders, and drug, psychodynamic, and behavioral treatments. Part Two deals with specific disorders such as mood disorders, chronic depressive disorders, phobias, panic, obsessive-compulsive disorder, sexual somatoform, and borderline and antisocial personality disorders. Part Three covers special populations, with chapters on marital dysfunction, adolescents, geriatrics, Vietnam veterans, mentally retarded adults, and mentally ill substance abusers. Part Four addresses special topics such as ethical and legal issues, suicide, office practice, and research in outpatient clinical practice. Chapters are lengthy, and go into considerable detail and are accompanied by lengthy bibliographies. There is a subject index but the book lacks an author index, which it needs. The overall organization of the book moves from more general theoretical issues to specific disorders, populations, and situations. The general approach is so applications-oriented that theoretical considerations are kept to a minimum. Nonetheless, the theoretical orientation appears to be fairly eclectic, if somewhat limited to the traditional dichotomy of psychodynamics as contrasted to behaviorism.

The work is intended for practicing professional and graduate students in clinical programs, and is thus suited to academic libraries as well as perhaps some medical libraries or libraries of public welfare agencies. What makes the book special is its unique focus on particular populations affected by the deinstitutionalization movement in recent years, in which thousands of patients were released from mental hospitals and are now treated by outpatient facilities. This group and their particular problems have been underrepresented in the literature and this handbook helps remedy this. 
Cynthia G. Last and Michel Hersen, editors. Handbook of Anxiety Disorders. New York: Plenum Press, 1988. 647 pages. ISBN 0-08-032766-4.

Cynthia G. Last and Michel Hersen are both listed here as being affiliated with the University of Pittsburgh School of Medicine. The other contributors to this volume are listed as having similar academic affiliations. The publisher is the well regarded Pergamon Press, and this volume is part of its general psychology series.

The editors' purpose, as stated in the preface, is to put the field of anxiety research into perspective by considering its many manifestations and recent growth. The book is divided into seven sections. Part One is an overview, while Part Two discusses clinical features and assessment, including diagnosis and classification, phobic disorders, obsessive compulsive disorder, panic and generalized anxiety and posttraumatic stress disorder. Part Three is about development and maintenance and includes chapters on genetics, animal models, pharmacologic models, psychophysiology, psychodynamics, stress and vulnerability, life events, and personality disorders and anxiety. Part Four covers psychological treatments, including psychotherapy, behavior therapy, cognitive approaches, marital and family therapy, and hypnosis. Part Five includes pharmacological treatments such as benzodiazepines, beta-adrenergic blockers, and tricyclic antidepressants. The sixth section is devoted to special topics, including childhood and adolescent anxiety, anxiety in the elderly, suicide and anxiety, illness and anxiety, and primary prevention of anxiety disorders. Part Seven outlines future directions. Chapters cover topics in depth and are followed by lengthy bibliographies. There are detailed author and subject indexes, as well as a separate biographical section about the contributors.

The book is intended for practicing psychologists as well as students, and would be appropriate for academic libraries, medical libraries, or community mental health centers. The principle thrust of the book is applied, but even within the section on psychological treatments, the approach seems limited to a narrow theoretical range. The chief value of this work lies in its ability to provide a quick overview, as well as an in-depth examination of research on anxiety, an area that has grown so fast over the past 20 years that it is difficult to contain in a single volume. Perhaps for this reason, the book represents something of an accomplishment, thus making it worthy of consideration.

Samuel M. Turner, Karen S. Calhoun, and Henry E. Adams, editors. Handbook of Clinical Behavior Therapy, Second Edition. New York: John Wiley \& Sons, 1992. 481 pages. ISBN 0-47163563-4.

Samuel Turner is associated with the University of Pittsburgh, Karen Calhoun and Henry Adams are with the Psychology Department of the University of Georgia. The other contributors to this volume are listed as having similar academic credentials. The publisher is the well known John Wiley \& Sons, and this title is part of the Wiley Series on Personality Processes.

This book is a completely revised and updated version of the first edition published in 1981. The editors' purpose is to document the continuing refinement of behavioral theories and treatment strategies as well as show their applicability to a broader range of clinical problems. The work is divided into four parts. Part One focuses on adult disorders such as simple phobias, social phobias, panic disorder, agoraphobia, generalized anxiety, obsessive-compulsive disorder, post-traumatic stress disorder, unipolar depression, personality disorders, schizophrenia, sexual dysfunction, paraphilic disorders, and substance abuse. Part Two is concerned with childhood disorders, including anxiety, depression, attention deficit-hyperactivity disorder, conduct disorder, mental retardation, and autism. Part Three covers behavioral medicine and takes up eating disorders, chronic pain, and disease prevention. Part Four includes chapters on family violence and behavioral marital therapy.

Each of the chapters gives an in-depth analysis of the topic and is well researched with extensive lists of references. The book includes both author and subject indexes for easy access. The organization of the book is somewhat odd, with the section on childhood disorders following the one on adulthood, when the natural progression would seem to be the reverse. The book is intended for clini- 
cians and for students, and this would be appropriate for academic and for medical and community mental health center libraries.

Theoretically the book is somewhat one dimensional because it only covers behavioral applications or that increasingly popular hybrid, behavioral-cognitive therapy, but at least the book does touch on a wide variety of disorders, including problems behavioral techniques have not traditionally been used to treat, such as schizophrenia and depression. As with Hersen and Bellak's Handbook of Clinical Behavior Therapy with Adults, this book will be of primary interest to the clinician with a strong behavioral orientation. If I had to choose between the two handbooks, I believe this one is the better choice, because it includes children as well as adults, and because the research is more up to date.

Michel Hersen and Cynthia G. Last, editors. Handbook of Clinical and Adult Psychopathology: A Longitudinal Perspective. New York: Pergamon Press, 1990. 459 pages. ISBN 0-08-(036101-3.

At the time that they edited this book Michel Hersen was affiliated with the University of Pittsburgh School of Medicine, and Cynthia Last with Nova University. The other contributors to this volume have similar academic affiliations. The publisher is Pergamon Press, and this volume is part of Pergamon's General Psychol-
ogy series.

The editors' stated purpose is to bridge the gap between what is known about childhood disorders and adult disorders, based on the belief that there is growing evidence to suggest a relationship be-
tween child and adult psychopathology for a number of disorders. The book is divided into fourteen parts. Part One is a general introduction, and includes a developmental perspective on psychopathology. Part Two covers major depression, Part Three is about bipolar disorder, Part Four treats depression, Part Five is devoted to anxiety disorder and agoraphobia, Part Six deals with social phobia, Part Seven with simple phobia, Part Eight covers obsessive compulsive disorder, Part Nine discusses overanxious disorder and generalized anxiety disorder, Part Ten is concemed with post traumatic stress disorder, Part Eleven covers conduct disorder and antisocial personality, Part Twelve looks at mental retardation, Part Thirteen is on alcohol abuse and alcohol dependence, and Part Fourteen has obesity as its subject. Each section contains two chapters, one on the problem as manifested in childhood, and one on the problem in adulthood. Chapters are brief but appear to be relatively thorough, and are accompanied by detailed bibliographies. Both author and subject indexes are included, as well as detailed biographies of the contributors. The book has a practical, applied emphasis, and appears to be intended primarily for practicing psychologists, though it would certainly be of interest to clinical students or interns serving practicums as well. It is suitable for academic libraries, and possibly medical and social welfare agencies also. What is unusual about this handbook is its unique developmental approach, in which an attempt is made to integrate child and adult problems by seeing them as a continuum. This runs contrary to most handbooks which tend to treat either childhood or adult problems, but not both. In rare instances where the two are found in the same book, they are also kept in separate categories. This phenomenon seems odd in light of the fact that psychology has long emphasized the impact of early experience on adult behavior. This book represents a pioneering effort at a more continuous holistic view of human experience and mental life and, as such, deserves to be considered as part of any serious collection in clinical psychology, or developmental psychology, for that matter.

John C. Norcross, editor. Handbook of Eclectic Psychotherapy. New York: Brunner/Mazel, 1986. 500 pages. ISBN 0-87630-422-6.

John C. Norcross is a psychologist affiliated with the University of Scranton, the University of Rhode Island, and Brown University. The contributors to this volume all have similar academic affiliations. Brunner/Mazel has been publishing social science literature for many years.

The editor's purpose is to fill a void in the clinical psychology literature for a comprehensive source and critique of systematic eclectic psychotherapy. The book is intended to represent a unique compilation of the historical, conceptual, clinical and research issues related to psychotherapy integration and eclecticism. It consists of three parts. Part I is a history and overview of eclectic 
psychotherapy. Part II contains the actual eclectic approaches, including chapters on multimodal therapy, systematic eclectic psychotherapy, the transtheoretical approach, functional eclectic therapy eclectic time limited therapy, structural-phenomenological approaches, eclectic family therapy, eclectic casework, and a critique of leading eclectic approaches. Part III is concemed with concepts, research, and directions. It discusses underlying assumptions, the possibilities and promise of eclectic therapy, training eclectic psychotherapists, the implications of psychotherapy outcome research for eclectic therapy, and future directions in psychotherapy integra-
tion.

Each of the chapters in the book is well researched and includes a lengthy bibliography for further reading. The chapters also follow a standard format to facilitate easy comparison. There are detailed author and subject indexes to assist in accessing the material. The presence of chapters on phenomenological approaches and the effort has been made by eclectic therapies suggest that a genuine coverage of the subject.

The editor has intenc ing clinicians, as a tended this work to serve as a guide for practictheoreticians and educators. The students, and also as a resource for and research libraries, ane book is appropriate for academic and research libraries, and perhaps some medical libraries and puba growing trend, as elions as well. Eclecticism in clinical psychology is prochement, convergence, and by general movement toward rapeighties Given itsere, and integration that characterized the examining the subject is to importance, this effort at systematically serious collection of is to be lauded and deserves to be part of any serious collection of clinical psychology works.

Richard A. Wells and Vincent J. Giannetti, editors. Handbook of the Brief Psychotherapies. New York: Plenum Press, 1990. 604 pages. ISBN 0-306-43270-6.

Richard A. Wells is a psychologist at the University of Pittsburgh and Vincent $J$. Giannetti is at Duquesne University. Most of the
contributors to this volume have similar academic affiliations. Ple- num Press has an established reputation for publishing in the social sciences.

The stated purpose of the editors in compiling this handbook is to stimulate reflection, research, and experimentation with clinical practice and policy at both micro- and macrolevels. It is intended to be comprehensive by including all major theoretical orientations, affording the practicing professional and advanced student access to state of the art accounts of the techniques and strategies of established and emerging brief therapies written by outstanding practitioners in each area.

The book is divided into five parts. Part One is an introduction and overview, covering therapeutic interaction, integrative models of short term therapy, and mental health policy. Part Two focuses on technical issues such as overcoming resistance in family therapy, cognitive behavioral therapy, interpersonal psychotherapy of depression, and crisis intervention. Part Three includes short term dynamic psychotherapy, cognitive therapy, cognitive behavioral therapy, interpersonal psychotherapy of depression, and crisis intervention. Part Four is concerned with family and marital brief therapies, and covers family crisis therapy, brief behavioral marital therapy, strategic psychotherapy, problem centered therapy, brief therapy for sexual dysfunctions, and individual therapy. Part Five is devoted to brief group approaches, including short term group therapy, social skills training, therapy groups for schizophrenia, brief crisis therapy groups, and psychodrama. Chapters are brief but well researched with detailed bibliographies. The book features a detailed table of contents and subject index, but needs an author index.

The coverage seems to be weighted toward family therapy and behavioral approaches, but there is some attempt at eclecticism too. This book is intended for graduate students and clinicians, and is suitable for academic and medical libraries and clinics. Though considerably less compact than Bellak and Siegel's Handbook of Intensive Brief and Emergency Psychotherapy, this work provides a valuable contrast to their individualistic, psychodynamic approach. 